\title{
The Effectiveness of a Cognitive Behavioral Counseling Program in Improving School Adjustment for the Gifted Teenage Students at King Abdullah Schools for Excellence
}

\author{
Ziad M. Alkhazaleh \\ Faculty of Educational Sciences, The Hashemite University, Jordan \\ Received August 5, 2020; Revised September 17, 2020; Accepted October 19, 2020
}

\begin{abstract}
Cite This Paper in the following Citation Styles
(a): [1] Ziad M. Alkhazaleh, "The Effectiveness of a Cognitive Behavioral Counseling Program in Improving School Adjustment for the Gifted Teenage Students at King Abdullah Schools for Excellence, "Universal Journal of Educational Research, Vol. 8, No. 11B, pp. 6327 - 6339, 2020. DOI: 10.13189/ujer.2020.082272.
\end{abstract}

(b): Ziad M. Alkhazaleh (2020). The Effectiveness of a Cognitive Behavioral Counseling Program in Improving School Adjustment for the Gifted Teenage Students at King Abdullah Schools for Excellence. Universal Journal of Educational Research, 8(11B), 6327 - 6339. DOI: 10.13189/ujer.2020.082272.

Copyright $\bigcirc 2020$ by authors, all rights reserved. Authors agree that this article remains permanently open access under the terms of the Creative Commons Attribution License 4.0 International License

\begin{abstract}
This study aimed at recognizing the effectiveness of a group counseling program, based on cognitive behavioral approach in improving the level of school adjustment for a sample of gifted teenage students at King Abdullah II Schools for Excellence in Jordan. The study was implemented on a population of (132) students including the study sample (30) students. The students were equally divided into (15) students as an experimental group and (15) students as a control group. The researcher developed the study instruments: school adjustment scale, the semi-structured interview and the counseling program consisting of (14) sessions. After verifying their Psychometric characteristics, the counseling program was applied to the study sample. Based on the statistical analysis of the arithmetic means and standard deviations, as well as (One Way ANCOVA) analysis the study results indicated the existence of statistically significant differences in the level of school adjustment among the members of the experimental and control groups, in favor of the experimental one. According to these results the current study would be a qualitative addition in its field as it used the operational approach unlike most of previous studies which used the descriptive one. In light of the study results, the study recommended that other studies benefit from the current study in empowering the gifted students in all their developmental stages. The current study would be
\end{abstract}

an added value in the field of increasing gifted students' adjustments to school which would eventually lead to their success and desired achievements in the academic and social aspects.

Keywords School Adjustment, Gifted, Teenager, The Cognitive Behavioral Approach

\section{Introduction}

The interest in the gifted students has recently increased as those students constitute a valuable wealth in building societies. This interest can be displayed through contributing to improving their abilities, capacities and energy. For example, the Agency for the Advancement of Teaching and Innovation of the Talented (ADVA) was the first series of books to be established on an international level. This agency (institution) exclusively focuses on creating and developing innovation and talents, through investing in the endeavors of the workers in the fields of psychology, philosophy and education, in line with their efficient existence in their family, school environments and all civil institutions of the society [1].

Despite the increasing interest in the gifted students, 
some of their needs and challenges they face haven't yet received the due attention or sufficient research. This fact can be due to false convections (conceptions) that they do not need care and that they are in no need of any counseling services as they possess special abilities and they can learn and succeed on their own, without any considerable problems or difficulties [2,3].

Moreover, the needs of the gifted students in their schools, might have been ignored in advertently [4]. As they face different big challenges in their school environment. Foremost among which, are the high expectations held by their teachers and parents. This in turn constitutes great burdens for those gifted students and causes them psychological pressures and suffering.

On the other hand, the gifted students may suffer from various emotional problems, such as feeling of general anxiety and others. This is due to the unrealistic expectations of their families and teachers [5]. These false conceptions might be the most dangerous thing the gifted students face. They in fact confront a number of challenges, difficulties and problems that might lead, in its severest form, to psychological, social, family, academic, and school maladjustment. They are liable to different problems, of which some can be dealt with by the gifted students and others that need help and family or school intervention especially on the part of the psychologist [6].

Misunderstanding may occur between the gifted students and their parents or teachers regarding the gifted traits and characteristics, where the gifted students don't comply or get along with social norms and social compatibility. Students' analytical way of thinking may lead to their rejection of authority or subjugation to others. These attitudes or positions might affect the level of gifted student's adjustment to family, peers and teachers, which in turn, may lead to further stress and anxiety on the part of the talented student [7].

On the other hand, some gifted students may suffer from family problems represented in the poor parents' contribution, lack of care of their children's opinions, weak support, encouragement or appreciation of their achievements, following unsuitable traditional methods, which may result in behavioral problems at school. This necessitates creating special teaching and counseling programs that fulfill their aspirations and cater for their needs to prevent the aggravation of these problems [8].

Understanding and realizing the possibility of talented students, having special educational, personal, family, social, and psychological problems, is the key element that would enable teachers, counselors and parents to support and assist the gifted students with problems and help them realize that they are not alone [9]. In many cases, the academic needs of the gifted students at school are not fulfilled, as they need special programs, services and activities. This may be due to the great failure in the evaluation of the gifted students in their schools, regarding their exceptional mental abilities or outstanding academic performance [10]. The proper identification of the gifted students at the school, in a sound way, may be a difficult task, due to the difference in the international standards of those students. Therefore, we first have to discover what the gifted students need at school [11].

The function of the school counselor has developed, according to the students' needs. It is no longer exclusive to the familiar traditional roles like counseling or others. The school councilor's roles did not care much for students' needs and interests, according to their developmental stages. Nowadays, we notice that the school counselor roles have become comprehensive, in terms of rehabilitating students psychologically and assisting them to achieve the highest levels of psychological adjustment to the school environment and its surroundings, as well as working with different groups of students most important of which are the gifted ones [12].

For instance, the school counselors can refer to ASCA Guide, under the heading" School Counselor and gifted Students Programs" that provides a brief justification of how aware the school counselor of the gifted students developmental, characteristics and interests such as 1 : identifying the gifted students; 2 - carrying out activities and consultations that cater for the academic , professional, personal and social needs of the talented students , through individual and group, counseling; 3- providing the resources and materials; 4 - increasing awareness regarding issues pertaining to talent; 5- Engagement in the professional development activities concerning the talent . School counselors can also refer to NAGC under the heading "Caring for the Social and Emotional Development for the gifted Children" which includes the following assertion: the gifted youth deserve due attention to their welfare and their unique international developmental experiences [13].

On the other hand, a lot of gifted students might face maladjustment to their school learning environment, which could lead to the feeling of boredom, lack of attention, lower academic achievement, and occurrence of problems in the classroom. Moreover, a lot of gifted students may not conform with their ordinary colleagues in the classroom, which in turn could lead to a sense of alienation, loneliness and miss understanding [14].

It is clear that good relations between the teacher and the students facilitate the process of the academic achievement and make a big difference in the wider psychological variables such as self-esteem, welfare, and self confidence among the students, particularly if the teachers are able to show respect towards their students, and provide them with emotional support in the classroom. This will have a significant influence on the students' behavior towards the school especially in the early adolescence period. Several studies showed that after the transfer from the elementary to the high school, there was a decrease in the students' realization of the emotional support, and their sense of belonging to the school [15]. 
For example, during the period of adolescence, the relation of students also changes, in terms of social comparison, as well as their feelings towards themselves and others. In the school stage, students spend a lot of time with their peers and have a big opportunity to monitor and evaluate the characteristics of their peers [16].

Furthermore, we find that teenagers experience a vast set of behaviors that distinguish them from adults and children, which makes this stage greatly special. Adolescence is certainly the period, during which the teenagers test the behaviors models they want to follow. During this period, they shape their general and personal identities [17]. According to Ericson, the central mission of adolescence is to create a strong and intense feeling of the personal identity, which often leads to confusion in the adulthood stage. Adolescence is a period of rapid physical and psychological development, which signals the transfer from childhood into adulthood. It is the period during which, they develop their self-identity, and their moral values. Moreover, they become more independent, they then are able to establish deeper relationships with their peers [18].

The period of adolescence constitutes a typical developmental transfer between childhood and adulthood, when the teenager learns how to be relatively independent from parents [19]. Teenagers confront some special and unique pressures, which arise from seeking more independency from parents and school [20]. This period was labeled as a period of storming and stress by developmental psychology theoreticians [21].

The teenager health has long been a decisive and essential element in the welfare of societies [22]. Therefore, teenagers throughout their academic stages need consultation and advice from a specialist or a counselor who takes into consideration adolescence psychology and looks into some resultant hazards [23]. So, providers of counselor services care for recognizing developmental needs of adolescence. Many organizations of professional 1 mental health, such as, American Counseling Association (ACA) and American Psychology Association (ABA) and American School Counselor Association (ASCA) are working on setting a code of conduct for the psychologist in terms of how to run the counseling process, through drawing up remedial plans, based on the different psychological approaches [24].

Counselor roles with the students at schools varied according to the psychological attitudes, on which they adopt ,for example self-centered thinking and the desire to be independent are considered as characteristics of adolescence psychology, which constitutes a challenge with some psychological interventions especially the remedial trends that explain people's behavior according to the cognitive structures of individuals ,most prominent among which is the process of cognitive behavioral counseling. Arrogant teenagers may not be able to recognize a different perspective or approach of thinking.
Likewise, mentality of (all or nothing) is common among them. And the conviction of (I must be ideal might lead them to suppose or surmise that their work is not good enough. This may cause them to feel stressed or unhappy. They might repeat the phrase (I'm a failure) which might lead them to assume it is no use trying in their school works tasks. Also the belief (Nobody loves me) might make them assume that others would not be kind to them. They might also suffer from mood swings (mercurialness). At one time, a teenager may appear depressed or anxious at other time they appear happy or comfortable [18].

As is agreed upon, the cognitive-behavioral treatment (CBT) explores the relationship between the individual realization and their emotions and behavior in a specific context. Therefore, we can say that what distinguish the CBT is its contribution in the work with the young people who suffer from complicated problems and are unable to access the common treatment types. Some teenagers might hesitate to attend cognitive-behavioral treatment at clinic, school or home. Or these young people may be socially isolated (unreachable). They may have problems of dangerous behavior for both themselves and others. This type of treatment constitutes a successful challenge to the way the teenagers think [25]. The cognitive-behavioral treatment is based on targeting any negative ideas or cognitive distortions that might contribute to ineffective communication among the teenagers [26].

The members of School Counseling Association in Indiana [27] consider the program of counseling and guidance as an integrated and essential part of school learning programs. They consider all school counselors as important leaders in designing such educational programs, with all the school workers to create an authentic educational environment of a high productivity and efficiency. So the parents have to participate effectively in designing the plan for all the essential educational programs, which would reflect positively on the output of education and its quality.

The school counselor usually plays a vital role in achieving the maximum level of success for the student, through the principal of leadership and cooperation to protect their rights, by providing a safe educational environment working to protect the human rights for all members of the school community as well as the ability to identify their needs represented by the preventive and intervention programs, by taking into consideration their relevant culture which constitute part of the comprehensive school counseling program [28].

The purpose of the counseling program in schools is to evaluate and support the teaching processes for the students and enables them to achieve success and develop them into becoming contributive members in their societies. It also supports their personal development and prepares them to become responsible, educated citizens and active workers and members in the family care. The counseling program prepares scientific plans to face challenges preventing the 
fulfillment of students' needs as well as presenting the suitable and proper consultation to the students and their parents [29].

\subsection{The Study Problem and Questions}

The suffering of the gifted students at their schools may arise from - problems of various sources. One of these sources may be due to peers or teachers. Misunderstanding the special needs of the gifted students may lead to threatening their psychological safety and generate feelings of tension and anxiety among them. Moreover, Reis [30] indicates that some gifted students may show feelings of anger and resentment due to the bullying of others as well as imposing opinions that may not conform with their cognitive structure, which may lead to their anxiety, tension and dissatisfaction. In this context, Alkubaisi and Huwaidi [31] stress the fact that despite the various positive characteristics and qualities the gifted students enjoy, they may face other problems and difficulties that the ordinary students do not. These difficulties and problems may not be because they possess talents, but they may be due to their behavioral qualities and traits or characteristics, other may be due to community, environmental, school or family factors.

As is agreed upon, talent accompanies the individuals throughout their different developmental stages from childhood until adulthood. But adolescence stage or period has a special character. It constitutes a source of psychological stress for both the gifted and ordinary people. However, identity formation or shaping among the talented takes a hard course, given the nature of the thoughts the gifted have of themselves. The gifted may have distorted or unreasonable thoughts towards themselves or others, especially if these thoughts are linked to the talent. To name but few, for example, (perfectionism). For all these considerations, the concern for methods of preparing the gifted at schools has increased, as schools are considered the social institution that the child deals most with outside the family. Based on the great role played by the psychologist, in the process of counseling and guiding the gifted students and helping or assisting them in solving the problems related to their educational environment, throughout their developmental stages, there came the study problem in answering the following question: What is the effectiveness of a cognitive behavioral group counseling program in improving the level of school adjustment among a sample of gifted adolescent at King Abdullah Schools for Excellence in Jordan?

The following two sub - questions spring from the main question:

What is the effectiveness of a cognitive behavioral counseling group program in improving the level of school adjustment for a sample of gifted teenage students at King Abdullah Schools for Excellence in Jordan?

Are there statistically significant differences between the two arithmetic means of the estimations of members of the study sample - gifted students - due to the group variable?

\subsection{The Significance of the Study}

Due to the fact that many previous studies exclusively touched upon the descriptive aspect rather than experimental or operational aspect in dealing with the gifted students problems, this study aspires to be the foundation stone for the operational counseling programs in the field of innovation and gifted. Hence it can be said that the current study could be an added quality and a rich source for the operational psychology, related to the talented counseling and excelling teenagers. In addition, this study provides study instruments with acceptable validity and stability coefficients that are suitable for the Jordanian society.

\section{Materials and Methods}

\subsection{Methodology}

The researcher used the semi- experimental method, whereby the students' sample was divided into two groups so as to recognize the effectiveness of the counseling program (independent variable) in improving the level of school adjustment (dependent variable).

Accordingly, the study design is as follows:

E G: 01 X O2

$\mathrm{C}$ G: $\mathrm{O} 1 \mathrm{X} \mathrm{O} 2$

O1 = PRE- MESURMENT

02=POST- MESURMENT

$\mathrm{X}$ : TREATMENT

E G: Experimental group

C G: Control group

\subsection{Study Population and Sample}

The study sample consists of all the students enrolled in King Abdullah II Schools for Excellence. The study population was (132) students from the $9^{\text {th }}$ and $10^{\text {th }}$ grades, according to the statistics provided by the concerned parties at the Department of Education at Zarqa Governorate. The scale was applied to whole population. It turned out that (32) students had problems with school adjustment, according to the results of the scale prepared for that purpose. The principal of the schools, as well as the students' parents were contacted for the implementation of the school adjustment scale on the students. 30 students agreed to participate in the group counseling program designed to increase their school adjustment. The researcher coordinated with them on the mechanism to accept the program and how to implement it at King Abdullah School for Excellence. The researcher also contacted the school to ensure the availability of a suitable 
hall to train the talented students on the group counseling program designed for the targeted group. So the study sample was (30) students divided into two groups. The experimental group consisted of (15) students and the control group consisted of (15) students.

\subsection{Study Instruments}

\subsubsection{School adjustment scale}

The researcher developed a school adjustment scale, after referring to the relevant previous studies [32-35]. The scale, in its preliminary form, consisted of (55) items. Likert 5- point Scale was adopted to mark the school instrument by giving one point to each one of its 5 items (always, often, sometimes, rarely, never). Items were represented by the numbers $(1,2,3,4,5)$ respectively. The following measure was adopted for the purposes of results analysis: (1-2.23) low - (2.34- 3.67) moderate (3.68-5) high. The scale estimations were calculated through using the following equation: (The maximum limit of the scale (5) - the minimum limit of the scale $(1) \div 3$ ), then adding the answer (1.33) to the end of each category.

Marking the scale (School Adjustment Scale): In its final form, the scale consisted of (55) items. Five alternatives were used to answer the scales items: (always (5), often (4), sometimes (3), rarely (2) never (1)).

\subsubsection{The scale validity}

The researcher used the face validity, through using scale arbitration and presenting it to a group of specialists I the field of Special Education (10 persons). According to the arbitrary recommendations, the researcher deleted and added some items and maintained the agreed -upon items $(90 \%)$. The scale in its final form consisted of (50) items.

\subsubsection{The scale Stability}

Having completed the structure's validity procedures, the stability coefficient was calculated, by using reapplication, where the scale was reapplied to (20) talented students outside the study sample after two weeks of the scale first application. Accordingly, the stability coefficient was (0.84). Therefore, the study instrument was valid, stable or reliable, and applicable for the purposes of the current study.

\subsubsection{The semi-structured interview}

The semi-structured interviews are often used in the qualitative studies to investigate the ideas, sentiments or experiences in depth. They are the closest to reality. This technique contains open questions. These questions are designed to obtain open and detailed answers from the participants or those around them.

\subsubsection{The semi-structured interview Validity}

To verify the face- value, I formulated the first draft of the semi-structured interview. Five counselors, four specialists in statistics and evaluation, as well as five teachers were consulted to obtain their views. Three parents were also consulted. Later, an exploratory, experimental study was conducted with some gifted outside the study population, as well as with some teachers and parents, to check the validity and reliability of the interviews questions and procedures.

\subsubsection{Group Counseling Program}

The group Counseling Program aimed at increasing the level of the school adjustment for the gifted teenage students at King Abdullah Schools for Excellence at Zarqa city in the $9^{\text {th }}$ and $10^{\text {th }}$ grades. The program consisted of (14) counseling training sessions for which the time period ranged between (45 -60) minutes each. The program was implemented on students twice a week, based on their willingness to take part in the counseling sessions. The participating students were among those who recorded the lowest degree's rates on the school adjustment scale. The program implementation period was (7) weeks. Table (1) shows the counseling sessions, in terms of, titles, goals, and techniques. The objective was to make students more aware of or more conscious of their unreasonable internal thoughts using the techniques of cognitive-behavioral approach, among which are : Stress Inoculation Training, rebuilding the cognitive structure, and Assertiveness Training. The talented students learn some skills to assist them to cope with their unreasonable thoughts, which may cause them psychological stress and maladjustment, through identifying these unreasonable thoughts, linking them to the problematic behavior, doubting their thoughts and then modifying them . 
Table 1. Group counseling programs sessions

\begin{tabular}{|c|c|c|c|}
\hline $\begin{array}{l}\text { Session } \\
\text { No }\end{array}$ & Session titles & Goals & Techniques \\
\hline 1 & Orientation & $\begin{array}{l}\text { Setting the scene for acquaintance between counselor } \\
\text { and members. } \\
\text { Identifying limits \& Rules of the counseling } \\
\text { relationship. } \\
\text { Recognizing members' expectations from counseling } \\
\text { operation. }\end{array}$ & $\begin{array}{l}\text { Dialogue and discussion. } \\
\text { Role play. } \\
\text { Ice- breaking Drill. }\end{array}$ \\
\hline 2 & How to think 1 & $\begin{array}{l}\text { Introducing the members to their" recurrent thoughts" } \\
\text { according to Alice Philosophy. } \\
\text { Assisting members in understanding thinking aspects. }\end{array}$ & $\begin{array}{l}\text { Dialogue } \\
\text { Questions } \\
\text { Drill ( You Think) }\end{array}$ \\
\hline 3 & How to think 2 & $\begin{array}{l}\text { Increasing members' precognition of their thoughts } \\
\text { and emotions. } \\
\text { Providing members with Alice and Biak cognitive } \\
\text { points of view. }\end{array}$ & $\begin{array}{l}\text { Dialogue } \\
\text { Role Play } \\
\text { Precognition }\end{array}$ \\
\hline 4 & Unrealistic Automatic Thoughts & Assisting members to identify automatic thoughts & $\begin{array}{l}\text { Thoughts record. } \\
\text { Imagination }\end{array}$ \\
\hline 5 & $\begin{array}{l}\text { Automatic Thoughts and Confused } \\
\text { Behavior }\end{array}$ & $\begin{array}{l}\text { Getting members to realize that their automatic } \\
\text { thoughts are the reason of their confused behavior. }\end{array}$ & Filling the Vacuum. \\
\hline 6 & $\begin{array}{l}\text { Questioning members unrealistic } \\
\text { automatic thoughts } 1\end{array}$ & Refuting members unreasonable thoughts & Imagined Socrates Dialogue \\
\hline 7 & $\begin{array}{l}\text { Questioning members unrealistic } \\
\text { automatic thoughts } 2\end{array}$ & $\begin{array}{l}\text { Disputing of thoughts } \\
\text { Confrontation of thoughts }\end{array}$ & $\begin{array}{l}\text { Imagined Socrates Dialogue. } \\
\text { Self-Talk. } \\
\text { Homework }\end{array}$ \\
\hline 8 & Rebuilding Cognitive Structure 1 & $\begin{array}{l}\text { Reminding members of the relationship between } \\
\text { thoughts, behavior and emotions. } \\
\text { Introducing successful communication skills to } \\
\text { members }\end{array}$ & $\begin{array}{l}\text { Rules Change. } \\
\text { Role Play } \\
\text { Self- Talk } \\
\text { Homework }\end{array}$ \\
\hline 9 & Rebuilding Cognitive Structure 2 & $\begin{array}{l}\text { Teaching members the importance of positive Self- } \\
\text { Talk. } \\
\text { Enhancing members awareness of their behaviors in } \\
\text { the context( This and Now) }\end{array}$ & $\begin{array}{l}\text { Thinking Halt. } \\
\text { Self- Talk. } \\
\text { Homework. }\end{array}$ \\
\hline 10 & Rebuilding Cognitive Structure 3 & $\begin{array}{l}\text { Introducing Importance of Flexibility in Thinking. } \\
\text { Assisting members to express their Thoughts }\end{array}$ & $\begin{array}{l}\text { Distancing and concentration. } \\
\text { Displacement from Centre. }\end{array}$ \\
\hline 11 & $\begin{array}{l}\text { Inoculation against Psychological } \\
\text { Pressures } 1\end{array}$ & $\begin{array}{l}\text { Members getting to know Psychological Pressure. } \\
\text { Teaching members the sources of Psychological } \\
\text { Pressures. }\end{array}$ & $\begin{array}{l}\text { Cognitive Plan } \\
\text { Of Psychological Pressure. } \\
\text { Dialogue. } \\
\text { Homework. }\end{array}$ \\
\hline 12 & $\begin{array}{l}\text { Inoculation against Psychological } \\
\text { Pressures } 2\end{array}$ & $\begin{array}{l}\text { Members know steps of Inoculation against pressures. } \\
\text { Members are trained on cognitive -behavioral } \\
\text { Methods. }\end{array}$ & $\begin{array}{l}\text { Relaxation. } \\
\text { Self- Assurance. }\end{array}$ \\
\hline 13 & Self- Assertion & $\begin{array}{l}\text { Members introduced to Assertive Behavior. } \\
\text { Members trained on Assertive Behaviors Techniques. }\end{array}$ & $\begin{array}{l}\text { Assertive Approval. } \\
\text { Diffusing. } \\
\text { Assertive Containment. } \\
\text { Role- Play. }\end{array}$ \\
\hline 14 & Final Session & $\begin{array}{l}\text { Summarizing Previous Sessions. } \\
\text { Identifying extent of Projects Goals Achievement } \\
\text { (Implementing Post Measurements on Experimental } \\
\text { Group Members. }\end{array}$ & $\begin{array}{l}\text { Dialogue and Discussion } \\
\text { Self- Disclosure. }\end{array}$ \\
\hline
\end{tabular}

\subsubsection{The Program Validity}

To verify the face validity of the program, it was presented to group of referees comprising (10) persons from the teaching staff at the faculties of educational sciences at Jordanian and Saudi universities. Each one of them was handed a copy of the program related to the group counselling. The results of the referees were $90 \%$ positive and their remarks were taken into consideration.

\subsection{Procedures}

Having completed the special scale designed for the study and the training program, its evaluation, as well as extracting the validity and stability coefficients of the study, the following procedures were taken:

1. choosing the place of the study, explaining the idea of the study, and the study purpose to the principal of King Abdullah Schools for Excellence to obtain his consent and his cooperation for the implementation of the study at the schools.

2. Conducting preliminary qualitative semi- structured interviews with the study members eligible to participate in the counseling program. It's to be noted, that using the technique of qualitative research means 
recognizing the ideas, beliefs, attitudes, values and concepts that could be held by the gifted students towards themselves, their relationships with the school environment. They are in depth interviews to understand a state or previous experience or event, from a personal perspective, in consistent with the principle of the psychologist in the group counseling.

3. The study scale for school adjustment was implemented on the study sample consisting of (30) talented students.

4. The scale results were collected and it turned out that 21 students of the sample had had problems with the school adjustment.

5. The school principal and the students' parents were contacted to implement the program prepared to increase the school adjustments for their children.

6. (30) Talented students responded positively to the participation in the group counseling program designed to increase school adjustment among the talented students.

7. Members of the sample were randomly divided into two equal groups (experimental and control) with 15 students for each.

To check the equivalency of the two groups, the arithmetic means and the standard deviations of the school adjustment scale for the pre measurement were extracted or calculated according to the group variable (experimental, control). To clarify the statistical differences among the arithmetic means, (T) test was used, as shown in table (2).

Table (2) shows that there were no differences of statistical significance at $(0.05=$ a) due to the group variable (experimental, control) for the school adjustment scale in the pre-measurement. This result indicates group equivalency.

8. Pre-test for the two groups (experimental, control) was conducted on the school adjustment scale.

9. Starting the implementation process of the training program on the control group.

10. Following the end of the training program, the posttest for the two groups (experimental, control) was conducted on the school adjustment.

11. Conducting qualitative semi- structured interviews to get extra information in order to check the effectiveness of the group counseling program from some of the experimental group from one hand, and some of the teachers, parents and peers from the other hand.

12. Data were statistically treated and results were extracted.

Table 2. Arithmetic means, standard deviations and T test according to the group variable (experimental, control) for the school adjustment scale in the pre- measurement.

\begin{tabular}{|l|c|c|c|c|c|c|c|}
\hline & Group & $\mathrm{N}$ & Mean & Std. Deviation & $\mathrm{T}$ & df & Sig. \\
\hline \multirow{2}{*}{ School adjustment scale } & Experimental & 15 & 2.95 & .205 & \multirow{2}{*}{1.609} & \multirow{2}{*}{28} & \multirow{2}{*}{.119} \\
\cline { 2 - 6 } & Control & 15 & 2.81 & .271 & & \\
\hline
\end{tabular}

Table 3. Arithmetic means and standard deviations were calculated for the students' performance in the school adjustment in the pre and post measurements, according to the group (experimental, control)

\begin{tabular}{|c|c|c|c|c|c|}
\hline \multirow{2}{*}{ Tool } & Group & N & \multicolumn{3}{|c|}{ Pre } \\
\cline { 2 - 7 } & Experimental & Mean & Std. Deviation & Mean \\
Deviation
\end{tabular}

Table 4. The results of ANCOVA analysis for the post measurements of the students' performance on school adjustment scale according to the group (experimental, control) after neutralizing the effect of the pre measurement for them

\begin{tabular}{|c|c|c|c|c|c|}
\hline Source & $\begin{array}{c}\text { Sum of } \\
\text { Squares }\end{array}$ & df & Mean Square & F & $\eta^{2}$ \\
\hline Pre & 0.63 & 1 & .063 & .747 & .395 \\
\hline Group & 2.339 & 1 & 2.339 & .027 & .084 \\
\hline Std.Error & 2.281 & 27 & & & \\
\hline Corrected Total & 5.150 & 29 & & \\
\hline
\end{tabular}




\section{Results and Discussion}

Question 1: What is the effectiveness of a group cognitive behavioral counseling program in improving or upgrading school adjustment for a sample of gifted teenage students at King Abdullah Schools for Excellence, according to the group variable?

To answer this question, the arithmetic means and standard deviations were calculated for the student's responses to school adjustment scale in the pre- and post-measurements, according to the group (experimental, control) as shown in the following table (3).

It is clear from table 3 that there are faces or apparent differences among the arithmetic means of the students' performance on the school adjustment scale in the pre and post measurements according to the group (Experimental, Control).

To know if these apparent differences have statistical significance and valuable effect, (ANCOVA) was used to measure the students' post performance according to the group (experiment, control) after neutralizing the effect of pre measurement for them. Following is the presentation of these results as shown in table (4).

As shown in Table (4) it is clear that there are differences of statistical significance at $(0.05)$ for the students' performance on school adjustment scale according to the group (experimental, control) F value was (27.685) with $(0.000)$ which is a value of statistical significance, which means there is an effect of the group cognitive behavioral counseling program.

As shown in table 4, the effect of the cognitive behavioral group counseling program was relatively high. Ratio of Etha explained (50.6\%) of the predictable variance in the dependent variable, that's the improvement in school adjustment in a sample of talented students at King Abdullah School for Excellence in Jordan. To determine for which are the differences are attributable, the modified arithmetic means and their standard errors were extracted, according to the group, as shown in table 5 .

Table 5. The modified arithmetic means and their standard errors on the school adjustment scale according to the group (experimental, control).

\begin{tabular}{|c|c|c|c|}
\hline Tool & Group & Mean & $\begin{array}{c}\text { Std. } \\
\text { Error }\end{array}$ \\
\hline $\begin{array}{c}\text { School } \\
\text { adjustment scale }\end{array}$ & Experimental & 3.604 & .077 \\
\cline { 2 - 4 } & Control & 3.021 & .077 \\
\hline
\end{tabular}

The results in table (5) indicate that the differences were in favor of the experimental group, which was subjected to cognitive behavioral group counseling program in improving school adjustment for a sample of gifted teenage students in Jordan, in comparison to the members of the control group. This result can be explained in light of the positive effect of the effective relationship the researcher made with the members. This effect was apparent in the counseling sessions, where all members were motivated in more than an occasion to expose themselves before the leader and audience. This seems to be due to the researchers' keenness on introducing a constructive model of self-revealing with the members regarding ideas, thoughts and emotions and experiences. The leader is usually required to make active communication with the members of the group to ensure their sharing in their own emotions and thoughts [36]. Hence it seems that this unique experience the members went through contributed, in one way or another, in the transfer of these positive experiences into their relationship with their peers, teachers and even their families.

Moreover, this result or outcome can be explained in light of the positive effect that is due to the cognitive behavioral attitude or approach. Adopting this approach stress, the encouragement of self- awareness and precognition in the way they think. If we take this explanation as one of the strategies used in this context, it's based on understanding the latent or hidden motives behind their behavior and feelings or emotions. The cognitive structure constitutes the basic foundation in shaping their automatic thoughts, which in turn, affect their feelings and behaviors [37].

This study is consistent with previous studies on the efficiency of cognitive behavioral school counseling programs with the gifted students. (Studies [38-42]. The increase in the level of the school adjustment can be explained in terms of the decrease in the level of teenage gifted students stress following their training in cognitive behavioral treatment skills, the most prominent among which is (relaxation) noting that this period, the teenager mood is more confused than any time before. It can also be said that the talented sharing of their experiences with other members of the group contributed to providing the adequate opportunity to express their feelings and sharing them with others. Therefore, the results of this study are consistent with the results of studies [43-47]. In terms of the effect of the cognitive behavioral on the teenage gifted teenagers of which their results indicated the efficiency of school counseling programs for gifted teenagers.

The results of this study is inconsistent with that of the study [48] in which the results of student's evaluation of the counseling programs accompanying the teaching curriculums, indicating that they cared for and observed some of the gifted students needs and abilities, and not their all different and diverse aspects of their personalities. The results of the current study also are in contradiction of the study [34] which indicated that the field of counseling came at the first rank of the problems facing the gifted excelling students in the Pioneering Centers at AlBalqaa Governorate in Jordan. Next came the social, academic, family and personal fields respectively. The current study also is in contrast with study [49] which targeted the extent of concern of emotional needs, and the psychological and social development of the gifted teenagers, where it turned out through the program, that the low quality of group counseling and guidance services did not achieve their 
target in developing the emotional and social aspects of the students. The school counseling program did not abide by the criteria and recommendations of The National Association for the Welfare of the gifted. At the opposite side, this study started from the justifications and results of study [35] which indicated the emergence of school maladjustment problems among the gifted students.

To obtain more realistic results, and to increase the ability to explain results, the researcher adopted the qualitative method, through using semi- structured interviews with the members of the experimental group, and with essential people in their lives like parents and teachers especially peers in many cases. The texts of the written interviews constituted a common starting point for the analytical qualitative content. The goal of this analysis is to convert large amount or part of the text methodologically into very structured and brief summary of the main results. This is evident in the noticeable responses from some of the experimental groups members. Following is an example of the way how a member of the program (participant number 5) thought during the period from before joining the group to the end of the last counseling session.

Before joining the program, the researcher conducted individual interviews with the (participant no 5). This participant had unreasonable thoughts, resulting in his maladjustment with those surrounding him in school. Some of his noticeable ideas are clear in the following.

Dialogue:

Counselor: How do see yourself, compared to your peers?

Participant: I should always be in the first place among the peers. Only the first place suits me

Counselor: How do you do your homework?

Participant: I must do everything perfectly without faults. Otherwise, I will be worthless among colleges and teachers.

Counselor: How do you see your relations with your colleges?

Participant: Some colleges are evil and bad, they deserve to be punished and reprimanded

Counselor: Do you always feel satisfied with your life at school:

Participant: I feel frustrated a distressed when things go against my wishes.

Counselor: Can you solve any problem you face?

Participant: There is always a right and perfect solution to any problem that should be reached, otherwise things would not be all right.

During the course of the counseling sessions, this member started to back off from the unreasonable method he thinks of. He became more flexible in his ideas. This is due to the methods and strategies adopted by the counselor in the counseling program, based on the cognitive and behavioral treatment. Some of its steps are as follows: identifying the unreasonable thoughts, linking these thoughts with the disordered behavior, doubting member's unreasonable thoughts, modifying these unreasonable thoughts. The successful strategies used by the counselor, in running the counseling session contributed to the members abandoning their unreasonable thoughts, including (participant 5) who started to think in a different manner than before. Therefore, I will present way the participant s started to adopt after the completion of the counseling program.

Counselor: How do you see yourself, compared to your peers:

Participant: I Prefer to in the first position, I trust myself and I seek to compete honestly.

Counselor: How do you do your homework?

Participant: I do my best to accomplish my homework. There is no perfect person. I have respect among my teachers and colleges.

Counselor: How do you see your relations with your colleges?

Participant: I have good faith in my colleges intentions, we need each other.

Counselor: Do you feel satisfied with your life at school?

Participant: Thank God, I feel satisfied because I often achieved what I want.

Counselor: Can you solve any problem you face?

Participant: I seek to solve my problem on my own. But I might need help. Therefore, I'm in lack of nothing.

On the other hand, through the interviews the researcher conducted with some teachers to talk about their opinions about the behavior of the students after the completion of the program, it turned out, that the conduct of the students improved considerably. One of the teachers said, the students became happy, always laughing, optimistic, engaged, obedient and cooperative.

Moreover, in order to make the picture more comprehensive and realistic, about the changes in the gifted students, the researcher was keen on meeting the participant peers in the program. Peers demonstrated relative comfort regarding the member's behaviors. Their complaints on the behavior decreased. Some peers frankly admitted: I no longer feel disgusted from others. I don't feel their superiority, on the contrary I became happier with them.

Finally, the researcher contacted parents of the participants gifted in the experimental group to identify the extent of satisfaction and approval of their sons in the counseling program, the parents commended the researcher efforts and thanked the counselor researcher for his endeavors in bringing about the great change in their behavior. One of the parents said: My son has actually become cooperative, tolerant, and his anger has decreased when talking to him.

Question 2: Are there differences of statistical significance between the two arithmetic means for the study sample individuals - the talented teenagers - on the tracking school adjustment scale attributable to the group 
variable?

To answer this question, the arithmetic means and standard deviations were extracted for the school adjustment tracking scale according to group variable (experimental, control). To clarify the statistical differences among the arithmetic means, a (T) test was used as shown in Table (6).

Table (6) shows that there are no differences of statistical significance (0.05) Attributable to the group (experimental, control) in the tracking school adjustment measurement.

This result can be attributed to several factors among which are: participation in the group counseling program which provide the participants with a suitable atmosphere in learning, training, as well as providing pre planned techniques to help the participants transfer the effect of learning outside the framework of counseling program. This result can also have explained in terms of the content components of the programs that are thought to contribute to the previous results indicating an increase in the level of school adjustment for the gifted students. These components were developed through reviewing referring to previous theoretical literature of the subject which dealt with methods techniques of gifted counseling as well as training them in using these methods and encouraging students to practice them outside the counseling sessions, in addition to following up their practices outside the counseling sessions. Consequently, practices make students more convinced about these methods. It's noteworthy that the homework given to students was live and rich experiences in the gifted comprehension and precognition of their lives. The researcher was keen on following these home works and discussing them with the participants in the following session. Therefore, these factors made students better than before, in terms of, their acquiring school adjustment skills, particularly, cognitive and behavioral ones, like (self- assertion).

We should also not forget the rapid developmental nature that characterized gifted students as they differ from most of their peers given that this developmental indication of comprehensive psychological, social and emotional development can arise from early childhood up to adolescence [13]. This factor help the members of the experimental group maintain the effect of the counseling program due to the fact that their developmental cognitive structure cause them to remember the lessons instructions and knowledge and skills well. These elements became part of their philosophy in dealing with life requirements.

Furthermore, we may attribute this result to the great and positive effect and the big role that King Abdullah Schools for Excellence play in providing the necessary material and emotional moral support as well as diverse activities. The school officials provided all necessary things to implement counseling program sessions to ensure that all relevant activities and exercises implemented without any considerable difficulties or barriers or obstructions.

Table 6. The arithmetic means and standard deviations and (T) test for the tracking adjustment scale, according to the group variable (Experimental, Control)

\begin{tabular}{|c|c|c|c|c|c|c|c|}
\hline Tool & Group & $\mathrm{N}$ & Mean & Std. Deviation & $\mathrm{T}$ & df & Std. Error \\
\hline \multirow{2}{*}{ School adjustment scale } & Experimental & 15 & 3.55 & .297 & \multirow{2}{*}{$.213-$} & & 28 \\
\cline { 2 - 9 } & Control & 15 & 3.57 & .380 & & & .833 \\
\hline
\end{tabular}


Lastly, the results of the qualitative interviews can be referred to in terms of presenting a good and realistic explanation for the results of the second hypothesis. The second hypothesis investigates the factors and motives contributing to the maintaining of the effect of the counseling program among the members of the experimental group after the completion of the program. Then the researcher managed to interview some of the participants. The researcher tried to hold talks with them to recognize the way by which they still think, is it reasonable or not? Among some quotations taken from one of the participants, it turned out that he expanded his friendship with his colleges. This fact indicated that he became reasonable rational, he abandoned (should and shouldn't and expectations of evil from others, which represented a type of unreasonable thoughts. Moreover, it turned out, during the interview the extent of his satisfaction and happiness when talking of the school environment.

On the other hand, the researcher was keen on reaching the teachers again and interviewing some of them to know their opinions about the behavior of the participants, especially those teachers who pointed out their dismay at the student's behavior before enrolling into the training program. Among the questions asked by the counselor researcher to the teachers: did you realize the change that happened in their behavior? Did you recognize their feelings inside the classrooms? Did you realize the way they think in now? The answers indicated feeling comfortable and approval. The same is true for the peers.

Moreover, the researcher did his best to conduct interviews with some parents of the gifted students. During telephone contact with them, the parents showed approval of their son's behavior.

\section{Conclusions}

Gifted people are considered as one of the important segments of the society. Therefore, caring for them in schools is in general an Immunization against Psychological Pressures 1 essential factor to ensure the development of their talents without any problems. Hence, the big burden lies on the shoulder of the psychologist.

Since, the psychologist is the most qualified person to understand their interests. Due to the nature of the developmental stage that the gifted person goes through, they may face a great challenge in the social and school systems which might cause maladjustment or maladaptation with the school environment. Hence, it comes the role of the school counselor in adopting different counseling methods that assist them in solving their problems. The cognitive behavioral approach is considered the most successful methods worldwide in the field of counseling in terms of modifying the student's cognitive structures and providing them with constructive behavioral skills that enable them to adjust with their surrounding environment.

\section{Recommendations}

In light of the study results, the study came up with the following conclusions:

- Benefitting from the current study in empowering the gifted students in all their developmental stages.

- Benefitting from the current study to conduct further studies about the effectiveness of psychological counseling programs in improving the psychological welfare and adjustment for the gifted in all school stages from the elementary school until the university stage.

\section{Acknowledgements}

The researcher is extremely grateful to the cooperation of all students at King Abdullah Schools for Excellence, particularly those who were closely involved in this study.

\section{REFERENCES}

[1] Ambrose, D., Sternberg, R. Giftedness and Talent in the $21^{\text {st }}$ century: Adapting to the turbulence of globalization, Sense Publishers, 2016.

[2] Jarwan, F. Detection methods for the gifted, University Book House, Jordan, 2008.

[3] Ozcan, D., and Uzunboylu, H. School counsellors' perceptions of working with gifted students, South African Journal of Education, Vol. 40, No. 1, pp. 1-9, 2020.

[4] Kim, K., Kaufman, J., Baer, j., and Sriraman, B. Creatively Gifted students are not like other gifted students: Research, theory, and practice, Sense Publishers, 2013.

[5] David, Imre \& Balogh, Laszlo. Teachers opinon about -the nature of Giftedness, Act apsychologica Debrecina, No. 20, pp. 189-195, 1997.

[6] Addahiriu, S. Counseling Psychology: Modern theories and methods, Wael House for Publishing and Distribution, $\left(1^{\text {st }}\right.$ ed $)$ Amman, Jordan, 2005.

[7] Habib, M. Development of creativity in different stages of childhood, the Anglo Egyptian Library, Cairo, Egypt, 2002.

[8] Howe, A. Sustained, intensified effort is most often recalled by those in the "manufactured of creative achievements", The assumption that genius, Developmental psychology, Vol. 26, No. 6, pp. 187-196, 1999.

[9] Yewchuk, C., and Jobagy, S. The Neglected Minority: The Emotional Need of Gifted children, Education Canada, Vol. 31, No.4, pp. 8-13, 1992.

[10] Pfeiffer, S. Essential of gifted assessment, John Wiley \& Sons, 2015. 
[11] Conklin, W. Differenitation the curriculum for gifted learners, Shell Education Publishing, Inc., $2^{\text {th }}$ ed, 2015.

[12] Stone, B., and Dahir, A. TH The transformed school counselor. Boston, MA, 2006.

[13] Wood, S., and Peterson, J. Counseling gifted students: A guide for school counselors, Springer Publishing Company, 2018 .

[14] Pfeiffer, S. Serving the gifted: E vidence-based clinical and psychoeducational practice, Taylor \& Francis Group, 2012.

[15] Coleman, J. The nature of adolescence, Taylor \& Francis Group, $4^{\text {th }}$ ed, 2011.

[16] Ryan, A., and Ladd, G. Peer relationships and adjustment at school, Information Age Publishing, Inc., 2014.

[17] Fine, G., and Fine G. Gifted Tongues: High school debate and adolescence culture, Princeton University Press, 2001.

[18] Stallard, P. Thinking good, feeling better: A cognitive behavioral therapy workbook for adolescents and young adults, John Wiley \& Sons, $1^{\text {th }}$ ed, 2019.

[19] Egner, T. The Wiley handbook of cognitive control, John Wiley \& Sons Ltd, $1^{\text {th }}$ ed, 2017.

[20] Hagell, A. Changing adolescence: Social trends and mental health, Policy Press, 2012.

[21] Przepiórka, A. Family life in adolescence, Walter de Gruyter GmbH, Berlin, 2014.

[22] Bhabha, J. Human Rights and adolescence, University of Pennsylvania Press, $1^{\text {st }}$ ed, 2014.

[23] Hanley, T., Humphrey, N., and Lennie, C. Adolescent Counseling Psychology: Theory, Research and Practice, Taylor \& Francis Group, 2013.

[24] Luk-Fong, P., and Lee-Man, Y. School guidance and counseling: Trends and practices, Hong Kong University Press, 2013.

[25] Graham, P., and Reynolds, S. Cognitive behavior therapy for children and Families, Cambridge University Press, $3^{\text {th }}$ ed, 2013.

[26] Springer, D., Rubin, A., and Beevers, C. Treatment of depression in adolescents and adults: Clinicians guide to evidence-based practice, John Wiley \& Sons, Inc., 2011.

[27] ASCA, School counseling program, occupational outlook handbook, 2010.

[28] Lapan, R. T., Gysbers, N. C., and Kayson, M. A. Missouri school counselors benefit all students. Jefferson City, MO: Missouri Department of Elementary and Secondary Education, 2007.

[29] Wright, V. and Cook, S. Online counseling: Learning from writing therapy, British Journal of Guidance and Counseling, Vol. 30, pp. 285-298, 2001.

[30] Reis, S.M. Talent Ignored, Talent Diverted: The cultured context underlying Giftedness in females, Gifted child Quarterly, Vol. 39, No. 3, pp. 162-170, 1995.

[31] Alkubaisi, R., and Huwaidi, M. The problems of Al-Fateh Center for Outstanding Students, and ways to address them, the seventh scientific conference for the gifted and talented, Vol. 1, pp. 65-112, Amman, Jordan, 2010.

[32] Gabriel, M. The relationship between the control center and both academic achievement and psychological adjustment for adolescents, Journal of Educational Sciences Studies, University of Jordan, Vol. 23, No. 2, pp. 358-378, 1996.

[33] Alwaida, S. Psychological counseling and talent: the adaptive reality of gifted students at the Jubilee School, Studies of Educational Sciences, Deanship of Scientific Research, University of Jordan, Vol. 29, No. 2, pp. 267-280, 2002.

[34] Alkharabsheh, O., and Arabiyat, A. The problems of gifted and talented students in the leadership centers in Al Balqa Governorate in Jordan and their indicative needs, King Saud University Journal, Educational Sciences and Islamic Studies. Vol. 3, No. 22, pp. 525-549, 2010

[35] Abu hawash, R. The problems of gifted and talented students in Al-Baha city from their point of view. Specialized International Educational Journal, Vol. 1, No. 1, pp. 1-16, 2012 .

[36] Jacobs, E., Schimmel, C., Masson, R., and Harvill, R. Group counseling, Strategies and skills, $8^{\text {th }}$ ed, CENGAGE Learning, 2016.

[37] Corey, G. Theory and practice of counseling and Psychotherapy, $8^{\text {th }}$ ed, Pacific Grove, CA: Books- Cole/ Wadworth, 2009.

[38] Alwalidi, A. The effectiveness of a behavioral cognitive counseling program in relieving the level of psychological pressure among a sample of gifted people in the Asir region, unpublished doctoral thesis, Umm Al-Qura University, Saudi Arabia, 2009.

[39] Sarah, M. The effectiveness of a group psychological counseling program in alleviating the emotional problems of gifted students in the elementary stage, unpublished Master Thesis, University of Babji Mokhtar Annaba, Algeria, 2011.

[40] Lahijanian, Z., Amiri, S., Moghtadaie, M., \& Malekpour, M. Efficacy of Cognitive-Behavioral Therapy on "Self-Perception" among Gifted Students with Learning Disorders. interdisciplinary journal of contemporary research in business, Vol. 4, No. 2, pp. 1091-1105, 2012.

[41] Abbas, N. A suggested counseling program to address the emotional and cognitive talent problems, Journal of Educational and Psychological Research, No. 50, pp. 173-195, 2016.

[42] Hamadanah, B. The effectiveness of a group counseling program in reducing the level of test anxiety and improving study habits among a sample of outstanding students at the College of Education at the University of Najran, Jordanian Journal of Educational Sciences, Vol. 13, No. 1, pp. 119-131, 2017.

[43] Alkhawaja, A. The effectiveness of a group counseling program based on the rational trend and problem-solving method to reduce psychological pressures facing distinguished students and develop their adaptation. Unpublished $\mathrm{PhD}$ thesis, Amman Arab University, Amman, Jordan, 2004.

[44] Wood, S. Gifted and Talented Adolescents' Experiences in 
School Counseling. (Doctoral dissertation). Retrieved from ProQuest Dissertations and Theses Database. (3209552), 2006.

[45] Maeali, I. The effectiveness of a treatment program in reducing psychological anxiety and developing self-concept among distinguished students, Al-Balqa Research and Studies, Vol. 17, No. 1, pp. 139-164, 2014.

[46] Alamrousy, N. The effectiveness of a psychological (cognitive-behavioral) counseling program to reduce the feeling of shame among a sample of teenage talents in Saudi society, Al-Quds Open University Journal for Educational and Psychological Research and Studies, Vol. 3, No. 4, pp. 111-155, 2015.
[47] Alqur'an, J., \& Alattili, K. The effectiveness of a group counseling program based on CBT in reducing stubborn behavior in early adolescent female students. Educational Science Studies, Vol. 43, No. 5, pp. 2105-2117, 2016.

[48] Alkhawaldeh, H. Evaluation of the talented curriculum in the special programs in the Hashemite Kingdom of Jordan from the viewpoint of teachers and students, unpublished Master Thesis, Amman Arab University, Amman, Jordan, 2006.

[49] Dockery, D. ways in which counseling programs at specialized high schools respond to social and emotional needs of gifted adolescents. Retrieved from ProQuest Dissertations and Theses Database. (3161256), 2005. 